\title{
The swinging cities of the eternal present
}

\author{
Mosè Ricci
}

\begin{abstract}
How many furnitures, or houses, or urban districts, that where designed and made in the 80 s are still relevant today? What clothes or shoes that period can be worn without appearing old or out of time? Everybody can say almost all. In forty years the living spaces have not changed that much. Even less their projects have been modified. The way in which they are conceived and designed is almost the same. Fashion, architecture, and cities are the sensitive forms that better represent the people that generated them. They express lifestyle, a status and, in some way aspirations and expectations for the future. Is it possible that they remained so indifferent to the changes of the last decades? A few times the distance between gestalt and zeitgeist was so dramatic. The paradigm that binds the aesthetics to the projection of time blowed up. The overcoming of modernity lies especially in this. We live like an eternal present. Where the sensitive forms and their representations in solid space no longer carry an idea of the future. They always seem to be more or less the same, immutable and increasingly deprived of sense in the rush of the sharing information technologies revolution that is distorting the system of social relations and the way in which things and places are related each other. Even today everything changes and so much faster than before. Innovation is conducted in the intangible areas of the net rather than in the material spaces. We live with our head in the Cloud. Objects are intended to produce informations that are monitored and transmitted in real time. Everything is accessible and traceable. The control is based on knowledge. In the era of the Internet of Everything, everything is destined to become another (as Marco Valsecchi wrote in February 2016 in the Sole 24 Ore Dossier on Technological Innovation). How the forms of living are changing, or will change? The architecture of the eternal present, paraphrasing Giedion (The Eternal Present, the beginnings of architecture. Pantheon Books, New York, 1964), is still able to propose innovation trough projects? The simultaneous action of three key factors: the economic crisis, the environmental one and the sharing information technologies revolution is so deeply changing our lifestyles and the way we imagine and we want the solid forms of our future that all our design knowledge suddenly seems inadequate both as an interpretative tool of the current condition and as a device capable of generating new environmental, social, economic performances and new beauty. Nothing surprising. In the history of architecture and the city the great technological changes have produced major changes in the lifestyles, in the forms of living and consequently in the way in which we design them. If the major paradigm of modernity was about the best possible spatial synthesis between function and architecture. Today, with the information technologies revolution, we have the opposite problem. To give meaning, narrative and uses-even temporary uses- to spaces that have already given forms and turn them into attractive and ecologically efficient places to live.
\end{abstract}

Keywords: Information technologies revolution, Eternal present, Recycle

Adam composes electronic music at home in Detroit. He almost never comes out. Eve lives in Tangier and she leaves to go see him. They are educated, beautiful

\footnotetext{
*Correspondence: mose.ricci@unitn.it

Department of Civil, Environmental and Mechanical Engineering, University of Trento, Via Mesiano 77, 38123 Trento, Italy
}

and vampires. Adam and Eve are privileged observers of the future of our world. They move trying to take bribes as little as possible from the ugliness of the present. In the crucial scene of the film Adam accompanies Eve in a night trip around Detroit. He tells her how dark and welcoming is the city in ruin. The last place to be for those who never die... And Eve replies This place will 
rise because there is water. When the South will burn the city here will be the life... Only those who love remain alive. Only those who know how to love forever. Those who respect the world they inhabit, his art, literature, the progress of science, the sound of the names. The others, those who believe they are alive only because their heart is beating, those who have lost the taste, the gaze and the dictionary are boring and dangerous creatures. They-the so-called human beings-are the real cannibals, the zombies. People who wake up always too late, that use and throw out, forgetful of the past, heedless of the future, mired in a present dark more than ever, even and especially in the light of the sun ...

Only Lovers Left Alive is a movie by Jim Jarmusch with Tom Hiddleston and Tilda Swinton that was in competition at Cannes in 2013. Is the story of Adam and Eve, coincidentally, two vampires. Of course the movie can be read as a metaphore that describes the contemporary urban age. It takes place in Detroit and is about those and the things who never die.

How many furnitures, or houses, or urban districts, that where designed and made in the 80 s are still relevant today? What clothes or shoes that period can be worn without appearing old, unusual or out of time?

Almost all we could say.

In 40-even 60-years the inhabiting spaces (clothes, furnitures, houses, districts, ...) have not changed that much. Their projects have been modified even less. The way in which they are conceived and designed is almost the same. Fashion, architecture and city neighbourhoods are the solid forms that better can represent the people that generated them. They express a lifestyle, a status and, in some way the aspirations and the expectations for the future. Is it possible that they remained so indifferent to the changes of the last decades?

These have been the years of the most profound technological revolution in history. More pervasive and effective than the one of the internal combustion engine at the end of the nineteenth Century that upsets not only the modes of production and the social hierarchies, but also the aesthetics and the solid shapes of living. When, with the second industrial revolution, all the material world changed very quickly. They invented urbanism. The architecture of iron and concrete generated new larger and larger cities. The art went futuristic and abstract. Lifestyles changed and clothes too. The modern world projected humanity in the future with its forms. The ideas of speed and of future expressed the zeitgeist in the design culture. As Bauman (2000) wrote in Liquid Modernity "modernity is time in the era in which time has a story". In modernity genius loci coincided with genius saeculi, the forms of the city, of architecture, of fashion fulfilled the epoch. In the modern age it was unthinkable to dress or to design furnitures, houses or cities as they did in the previous century.

Today it is no longer the case. The distance between gestalt and zeitgeist never has been so dramatic. The paradigm that binds the aesthetics to the projection of time blowed up. The overcoming of modernity lies especially in this. We live like an eternal present. Where the sensitive forms and their representations in solid space no longer carry an idea of the future. They seem to be always more or less the same. Immutable and increasingly displaced in the rush of the sharing information technologies revolution that is upsetting the system of social relations and the way in which things and places are related each other. Even today everything changes and so much faster than before. Innovation is conducted in the intangible areas of the net rather than in the material solid spaces. The way to experiment and disseminate informations and knowledge are especially mutating in a vortex of accelerated change where the tools and virtual synapses materials involve the activities and lifestyles linked to them while the more traditional and unconnected spaces tend to remain inert, equal to themselves. Or they change slowly.

Douglas Rushkoff, professor of media theory at the City University of New York, describes the impact of the information technologies revolution on society as the present shock. A crushing of the time in a myriad of parallel peripheries where everyone feels the need to live the instant in which everything happens. A disorientation that blurs past and future in a continue hyper-connection and creates an infinite present. He wrote: "The future that we have pursued for much of the twentieth century has finally arrived. Today the technology that we can dispose allows us to stay connected with anyone and to have at hand all sorts of information, at any time. But what will be the effect on our lives of this amazing compression of space and time? The era of the total access has a downside that we had underestimated. Social networks fuel the anxiety of a constant "here and now" without direction and priorities, fragmented and distracted. E-mail and instant messaging are now an assault; and we are overwhelmed by an illusory continuous present that always gets out of hand."

We live with our head in the Cloud. Objects are intended to produce informations that are monitored and transmitted in real time. Everything is accessible and traceable. The control is based on knowledge. In the era of the Internet of Everything, everything is destined to become another (as Marco Valsecchi wrote in February 2016 in the Sole 24 Ore Dossier on Technological Innovation).

How the forms of living are changing, or will change? The architecture of the eternal present, paraphrasing Giedion (1964), is still able to propose innovation trough 
projects? Is it still suitable, in other words, to express visions of the future for solid material spaces? And how those visions can and will make sense in the era of 4.0 technology?

Trying to give some answers to these questions it is best to go step by step.

The digital progress we have seen in recent years is certainly impressive, but it is only a clue of what will come. It is the dawn of the second age of the machines. To understand why this is happening now, we must understand the nature of technological progress in the era of hardware, software and digital networks. The rapid and always faster digitization will probably lead to more economic and environmental devastation due to the fact that becoming the computers most powerful companies will have less need for certain types of employees. Progress he will leave someone unemployed in its race, perhaps many people.

Brynjolfsson and McAfee (2014), two economists at MIT, developed those concepts in the book: The Second Machine Age: Work, Progress, and Prosperity in a Time of Brilliant Technologies - published in Italy by Feltrinelli in 2015-which tells us with great effectiveness the impacts of the sharing information technologies revolution for lifestyles and work processes.

The economic crisis is the first tangible result of the digital revolution that gradually reduces the job opportunities and empties the built spaces of the western city featuring new metropolitan figures. The technologies for sharing informations tend to transfer in the immaterial space of the Net functions and places that needed physical spaces to be realized until now. It is an obvious phenomenon at all. Just think about how are changing the behaviors of consumers that more and more now are buying on the net and there is less need for retail spaces in the city. You can meet, establish a relationship, give a talk via Skype or other social media without physically being there where it takes place. Now everything happens in the video, but soon our presence will be virtually expressed by holograms that can also simulate physical, emotion and meaning. Anyone can become a part time taxi driver and sell his travels on Uber or share the car with Car to Go or even the political choices at the click of Avaaz. In a few years with a 3D printer we can produce construction components and whole buildings. You can make at home spare parts of any object in common use and in a basically equipped laboratory also blenders and other machines. While the new figures of the digital artisans are emerging the appliances factories in Friuli and Veneto have already closed. All the computers become more powerful and smaller and smaller. New technologies have less need for physical space.
The ASCI Red, the first product of the Accelerated Strategic Computing Initiative of the US government, was the fastest supercomputer when it was introduced in 1996. To develop it had cost \$ 55 million and its 100 cabinets occupied nearly 200 square meters (80\% of a tennis court) at Sandia National Laboratories in New Mexico. Designed for tasks where needed so much computing capacity, such as to simulate a nuclear test, ASCI Red was the first computer to exceed the teraflops, a thousand billion floating point operations per second, in the classic test parameter for the speed of the computer. To get to this speed consumed 800 kilowatt per hour, about as much as eight hundred houses. In 1997 he touched 1.8 teraflops. Nine years later another computer touched 1.8 teraflops. But instead of merely simulating nuclear explosions was able to draw those and other graphics in all their magnificence realistic, three-dimensional, real-time. He does not do it for the physics community but for a video game. This computer was the PlayStation 3 of Sony, Red all 'ASCI equal in performance, however, cost about \$500, employing less than a tenth of a square meter, and consumed about 200 watts per hour. In less than ten years, the exponential digital progress has transferred the computing capacity at the level teraflops by a single state laboratory to the living rooms and the halls of the whole world. The PlayStation 3 has sold approximately 64 million units. The ASCI Red was withdrawn from service in 2006 (Brynjolfsson, McAfee 2015).

In just 10 years from a 200 square meters apartment to a mobile device that takes up less than a tenth of a square meter. This story is emblematic. Just to make it clear that not only the shared information revolution incredibly reduces the need for occupation of physical space, but also cancels the necessity of specialization of physical forms-removing the rationalist principle of Louis Sullivan Form Follows Function-simply because by using small digital devices we can do almost everything almost everywhere. Anyone can find thousands of similar examples that show how you always need less functional space to live and work because many of the uses that occupied real volumes in the city have been transferred or will transfer in the virtual spaces of the Net.

If all of this is about to happen or already it happens it is clear that many essential paradigms of modern, not only that of the close relationship between function and form of architecture or town, emptied of meaning. Ultimately the sharing information technologies revolution displaces the certainties of the modern project and it makes suddenly seem out of time all the theories and practices that relate to it. The zoning, the functional organization of urban or those architectural spaces, the models theories, the best practices... seem to manifestations of a logic 
that belongs to another era. They were designed to handle the expansions of inhabiting solid spaces that probably are no longer expected to grow up nowaday. For sure elarging footprint is no more the only possible project for the development of built spaces.

According to CRESME (an authoritative Italian observatory on the building market) and WWF reports 20072014, Italian cities have grown enormously in recent years. Between 1999 and 2009 approximately 300 million cubic meters per year were built up. It means 46 cubic meters per inhabitant. A building stock equal to about 70 apartments per square kilometer if we calculate the national territory minus the protected rural areas and woodland. Between 1999 and 2007 house values rise steeply: in over 8 years, from $+25 \%$ in the islands (i.e. Sicily and Sardinia), $+30 \%$ in the North, and $+60 \%$ in Central Italy. The same has happen with the number of buying and selling transactions, and the number of real estate agencies, architectural firms and construction companies. And the landscape has felt the impact of development just as much as the cities have. Between 1990 and 2005 a total of about 3.5 million hectares (a surface area as large as the Lazio and Abruzzi regions together) have been transformed. In Italy each Italian citizen makes use of 230 square meters of urbanized territory. There are more than $200,000 \mathrm{~km}$ of roads, $7500 \mathrm{~km}$ of disused railways, and 27 million homes of which $20 \%$ vacant. Each year, starting from the late 1990s, about 244,000 hectares of ground are consumed. With a game in which everyone believed to win-owners who put their savings safe, building companies working, the administrations that survived with urbanization taxes, policy that was continually prized by the rhythm of the building cycle-it was perpetrated a bloody and unprecedented invasion of Italian landscapes.

Since the collapse of the housing market in 2007 all the Country hit by the economic and environmental crisis suffer abandonment and disposal often also for more recent works. The results of the Survey into the Property Market drafted by the Parliamentary Commission for Environment, Territory and Public Works, carried out in 2010, clearly outline the actual urban condition in Italy. In the years from 2007 to 2010 there were 120,000 unsold flats, around $40 \%$ of those built. In 2010 the investments in the property sector dropped by $7 \%$, and new buildings by $32 \%$. The buying and selling transaction fell $(-15 \%$ in 2008 and $-19 \%$ in 2009) and in the three-year period 2006-2009 the business volume of the property market collapsed by $33 \%$. The same report highlighted that fact that in 2008 to purchase a house in the semi-central part of a large urban area an average of nine years of household income were required, as opposed to 3.4 years in
1965. The evictions for payment arrears went up by $25 \%$ between 2008 and 2009.

Moreover, there are 5.2 million empty houses out of 10 million unrented properties in Italy. If we exclude the first homes and the relative accessories and the other properties whose use could not be reconstructed or that have not been detected in the income tax declaration form, around 17.5 million property units are owned by private families. Of these not even one-third (that is, 29\%) is declared as being rented. It is very likely that out of this very limited share there is the impact of evasion. Or the vacant houses. In spite of the growing number of empty houses, in 2010 at least 230,000 families were living in a condition of cohabitation and 70,000 in precarious living conditions.

Even the numbers on the infrastructure reserve are significant. In Italy there are 20 million square metres of railway yards that are either disused or in the process of being closed down, of which around half ( 9.5 million) in metropolitan areas. In the meantime around $5000 \mathrm{~km}$ of railway line have been divested, of which $2600 \mathrm{~km}$ are still unused today. There are $20,000 \mathrm{~km}$ of abandoned roads of which 2600 unused. The Gioia Tauro Harbour, the Tiburtina High Speed Railway Station, the Bre-BeMi Speedway (and soon-we bet-the Expo) are only the most obvious examples of a policy that wastes always twice First insisting in building new fetishes of a passed modernity, and then wasting away the greatest historical and natural heritage all over the world. No enhancement devices or strategic investments are forecasted for that. The situation is the same in other European countries. In Spain between Madrid and Toledo is a kind of new city for 300 thousand inhabitants completely empty and unsold but built even with the rubbish bins and the lampposts. And even in the wealthier countries of northern Europe, the problem is very much present. The Dutch Pavilion at the Venice Biennale in 2010 was an empty room with the threat of plastic hanging from the ceiling of all the empty buildings of Ramstadt incumbent on the head of visitors. Biennale of 2012 always the Dutch Pavilion was called Reset and the German Reduce, Reuse, Recycle. In the 2014 Biennale Portugal is the Country that dramatically raises the same issue.

In just a few years the economic and environmental crisis has shown us that there is an important form of abandonment in Europe that is influencing the life and economy of the cities. It's a sort of abandonment that's not so much determined by an urban population decline, as by internal mobility, migration from manufacturing centers, excessive building, the marginal state of agriculture and the stagnation of the building market. All of these factors deeply affect the behavior and the wishes of 
the inhabitants themselves. In short, what's new is being abandoned. It is the abandonment of an idea of growth and the city, even before being an idea about its physical spaces. It responds to a strategy of survival, to the economic crisis and to the awareness of the environmental emergency. Its effects are evident, and across the territory they disseminate the image of a crisis-stricken city.

This is the point. The simultaneous action of three key factors: the economic crisis, the new environmental awareness and the sharing information technologies revolution is so deeply changing our lifestyles and the way we imagine and we want the solid forms of our future that all our design knowledge suddenly seems inadequate both as an interpretative tool of the current condition and as a device capable of generating new environmental, social, economic performances and new beauty.

If we look to the future it could be said that one crucial effect of sharing informations technologies revolution on the most advanced societies is the possibility of being able to live in much more physical space than in the past. A kind of space that it is not necessary to conform on the basis of pre-established specific fates. Simply, we dispose of a huge amount of built volumes that is no longer needed or do not yet know how to use. The same happens for infrastructure and open spaces.

Will Re-Cycle be the destiny of the design disciplines in an age that seems to consider only-or at least- with absolute priority the growth of not material spaces and the interconnection devices? If today -and in the future more and more- the theme of the development of the city is no longer about the growth but about the resilience and environmental quality? When not constructing new architectures, but retrofitting and re-signifying the existing ones becomes the central issue of the building production?

Returning to the initial question precisely, while everything is whirling changing ... clothes, houses and cities are apparently always the same. Is it possible to start reasoning about a new statute for the cities of the eternal present?

Nothing surprising. In the history of architecture and the city the great technological changes have produced major changes in the lifestyles, in the forms of living and consequently in the way in which we design them. If the major paradigm of modernity was about the best possible spatial synthesis between function and architecture. Today, with the information technologies revolution, we have the opposite problem. To give meaning, narrative and uses -even temporary uses- to spaces that have already given forms. And turn them into attractive and ecologically efficient places to live.

Kuhn (1962) in The Structure of Scientific Revolutions, clearly explains how in the early stages of scientific revolutions when major disciplinary paradigms are in crisis and are about to change, it is possible that two extreme theoretical positions contrast each other. One wants to substantially confirm the principles of the discipline. It tends to claim the specificity and uniqueness of the discipline in its traditional and absolute essence. The other uses curiosity as new knowledge device. He wants to challenge the established principles, pursue the paths of change, exploring other cultures and other worlds, acquire new disciplinary contributions, have different points of view on the future. It is a major challenge for the architectural culture. A challenge that gives value to the existing with conceptual devices that work on the slip way and new life cycles of living spaces. A challenge that sees the environment as a project, the landscape as an infrastructure that produces ecological performances and the future of the city as a collective and not authorial vision.

In everyday language a paradigm is a reference model, a term for comparison. The word comes from the ancient Greek paradeigma, which means pattern, example, sample. In philosophy of science, a paradigm is the framework of a scientific discipline. A comprehensive (and globally shared) vision of the world crystalizes around this framework. More specifically, it's the world in which the framework operates and the on which a specific scientific community concentrates. It constitutes and delimits the field, its logic and its research procedures, giving Leibnizian order to things. It is inside this paradigmatic logic that scientific research finds the object of study, the more cogent problems and the best techniques for dealing with them.

Kuhn (1962) used the following definition for the term paradigm: "The logical relationship between the main concepts that dominate all the theories and all the discussions that depend on them". As a result of being the "first unmoved mover", the paradigm must necessarily be shared by a community of scholars. Not by chance, only the more mature disciplines have a stable paradigm.

In that form, in normal science, a paradigm is the conjunction of experiments, based on models, that can be copied or emulated. The prevailing paradigm often represents a specific way of seeing reality or the limits on proposals for future investigation, which is something different from and beyond generic scientific method. Along those lines, a scientific revolution is characterized by a change in paradigm.

What here is perhaps more interesting is to understand is when and why it make sense to refer to the concept of paradigm speaking about recycle for the space design disciplines.

In other words whether it makes sense to inscribe the discourse on recycling within a wider theoretical frame 
that relates either to the huge scientific technological revolution that is now taking place, either to the obsolescence of the old disciplinary paradigms that unfit to understand the changes.

In the world of urbanism, architecture and landscape, a new paradigm is a new way of doing things that has a huge effect on the living spaces. New paradigm draws its roots from the idea of a paradigm shift in science, in which technology or new findings completely change the way people think about or interact with something. In the design disciplines the idea is the same; a whole new way of looking at lifestyles, living spaces and their changings. However they happen.

Detroit is the manifesto of the urban condition that identifies the new paradigm of recycling as a conceptual device for the cities in the age of the eternal present. Perhaps it is the most important in this phase of history.

Detroit is the American Pompeii. In 2001 Charles Waldheim and other scholars wrote in Stalking Detroit an extraordinary reportage of the crisis effects in the city (Daskalakis et al. 2001). As a result of the crisis of the economy that had generated it, the Fordist metropolis Detroit was forced to think about the problem of its survival and its fate. In the space of just a few years its population had fallen from 1850,000 to 740,000 , more than 2000 buildings had been knocked down, resulting in the abandonment of the center for an area with an approximately eight-mile radius that is glaringly evident. Detroit has more than 320,000 jobs lost between 2001 and 2008, and about $57 \%$ of the population having left the city from 1970 , and $25 \%$ in the past fifteen years: its public spaces are emptied of meaning and they not express a traditional urban figure, but suggest a new and different inhabiting way. Something that is impossible to imagine from an European perspective, that is impossible to imagine if you don't go there.

Detroit has one of the larger metropolitan area in the United States. Its perimeter could include together cities such as New York, Boston and Philadelphia. In the middle, in the famous eight mile divide of the Eminem' song, the modern city built in the last century with an elegant Victorian style, no longer exists.

The empty houses with walled-up windows, which is occupied by squatters, the tall buildings with windows crossed by birds, the demolished industrial areas, the abandoned shops, the empty monuments, have turned this city into something else. They have transformed this city in something that is much alike to an idea of park and this is not at all unpleasant. Beyond the ring of eight miles, around this new urban figure in the making, the suburb lives very well. That's where that the economic activities and houses are moved. In the peripheral area (a definition that could be obsolete elsewhere) there are well- travelled highways and shopping centres in full operating. The suburb works well in Detroit where the modern city ended with the collapse of the economy that had made it. Since 2001, perhaps from the book Stalking Detroit by Charles Waldheim, Georgia Daskalakis and Jason Young, the urban American culture has developed an important bibliography about the case of Detroit. The city has became a manifesto.

Many people have exalted the ruin's charm. The flying low images of McLean; the ephemeral urban condition documented by the short films of Zago; the Disassembled Detroit di Andrew Moore; the photo of blonde woman scarred that Jason Young shows during his lectures about Detroit; are the incisive icons of a dead body. It's the funeral of the modernity, It' the Ruskin's figure of derelict spaces of Detroit that slowly recolonized by nature. Media immediately popularized this figure and It has affected the collective imagination.

It is a charming and ancient vision that refers to The Stones of Venice or to Angkor Thom and Indiana Jones. It is a vision that can capture imagination and can attract tourism.

Thanks to Detroit United States also have their Pompeii. The romantic strength of the archeology of modernism captures the emotion of all and has in itself the idea of uniqueness. There is only one place in the world where you can experience live today the end of the modern city. That place is Detroit. No doubt about it.

The question is that in Detroit there is not only death and that what happens there can involve, or already involves, other places.

In Detroit it's happening something decisive for the Cities after the age of modernity that goes beyond the specific condition of the theme of ruin.

Today the best city tour is called Cloudspotting Detroit, Best Places for Viewing the Sky, sponsored by the city authorities. In spite of its name this tour takes the tourist (better if he or she is on a bike) to places that are interesting to visit, ones that are worth seeing if you come to Detroit. There actually aren't too many of them. Only 31 "places of interest" for American's 11th biggest city, formerly (?) a metropolitan center of 900,000 inhabitants living in the urban area (as compared with 2000,000 in the 1950s). What's important is that many of the top sixteen important places in the city are, as Alan Berger would call them, "drosscapes," while the others are evanescent. Demolished areas, potential parks, manholes emitting smoke produced by the underground heat, huge abandoned public buildings, markets selling second-hand objects or where you can just trade things, Victorian houses taken over by nature, houses occupied by squatters, re-naturalized infrastructures, abandoned areas that become sites for artistic installations...Clouds of dust, of 
vapor or flavors that take the place of traditional urban attractions (there are no architectures, museums, libraries, not even your grocery store in Detroit anymore) and they give the ruins of this Fordist city back to narrative dimension and to nature.

After 15 years since the acme of the disaster that struck the city, Detroit is finding, slowly, another dimension. For the first time in autumn 2011-and in percentage more than anywhere else in America-increasing housing prices and new inhabitants. The presence of the university as a stronghold, the reception of the first tourist numbers in restored Victorian villas, the repositioning of the stage to the city center, the casino in the Greek neighbourhood..., are all obvious symptoms of a city that begins to live in a different way.

New physical or intangible devices take the place of traditional urban shapes.

These are icons of the change that reduce, reuse and recycle the remainders of the city in a landscape.

The satellite images of telespazio; maps, diagrams and projects through which Stoss Landscape Urbanism develop proposals for the activation of the recycling processes at the urban scale; The Dan Pitera's experiments of reuse of homes burned (Fire Break) and unused spaces (TAP); the adaptation of the Michigan Theatre in a parking lot; "visions" focused on the practice of recovery told by Arens; build the epic of a city that experiences the possibility of another future after the metropolis. It is a process of recycling urban figure that generates new values through the assignment of a new sense of what is there. This is not a process of redevelopment or urban renewal. There isn't any attempt of the city regeneration or of Detroit's landscape of last century. There isn't an idea of restoration of a lost urbanity, but the creation of a new value through the reduction of traditional metropolitan functions, the reuse of derelict spaces and the recycle of urban surviving materials.

Detroit is the first post-metropolis. It is an urban condition that the literature about the city has already anticipated in different ways-from Jane Jacobs to Stanford Kwinter or Edward Sojia-and that not depends on the image of modern city returned to nature.

The post-metropolis is an urban figure that take advantage on spatial effects of an economical and social organization based on new media. This is why it separates itself from modernity and therefore does not need the same type of physical facts (infrastructure, housing models, industries, etc.) that representing the city of modernity.

In other words, the post-metropolitan condition of Detroit swings among the charm of ruins as the replacement of certain metropolitan materials with devices of instant artificial proximity (new immaterial infrastructures), and the harmony that urban life has found again in Detroit inhabiting unusual spaces and not necessarily fast.

The space settlement is freer to let nature happen. Ecology, sustainability, landscape, open spaces for leisure and kids, bike paths, slow mobility,..., all this becomes central to the performance and design of urban space.

They are all obvious symptoms of a city that begins to live differently and to convey the innovation. Ultimately it is just this. A recycling process of urban figure that generates new value by assigning new meanings to what already exists.

Recycling means putting back into circulation, re-using waste materials, which have lost value and/or meaning. Recycling protects the environment and it is economically convenient. It is a practice that allows you to limit the presence of waste, to reduce disposal costs and to contain those of the new production. Recycle means creating new value, new way. To begin a new cycle, in another life. In this lies the propulsion of recycling content. The very idea of recycling provides a vision. As detective of space the architects are interested in the possibility to revitalize the existing, to find new meanings for it, to create new conveniences and new beauty by the recycling built spaces that so rapidly are abandoning their characteristics of use. Recycle is an ecological action that operates pushing the existing into the future by transforming waste into prominent figures. In other words, as scholars of forms of physical space it is not interesting to adopt recycling paradigm because it is an ethical action -good and right-, but because in architecture today to recycle is to design.

The new paradigm of recycle projects into the future the reassuring image of the eternal present and twists it in a vision of beauty.

\section{Competing interests}

The author declares that he has no competing interests.

Received: 20 September 2016 Accepted: 20 December 2016 Published online: 21 January 2017

\section{References}

Bauman Z (2000) Liquid modernity. Polity Press, Cambridge

Brynjolfsson E, McAfee A (2014) The second machine age: work, progress, and prosperity in a time of brilliant technologies. W W Norton \& Co Inc, New York, London

Daskalakis G, Waldheim C, Young J (2001) Stalking detroit. Actar, Barcelona

Giedion S (1964) The eternal present, the beginnings of architecture. Pantheon Books, New York

Kuhn T (1962) The structure of scientific revolutions. University of Chigago Press, Chicago 